\title{
Bidirectional Association between Tooth Loss and Hypertension: A Systematic Review and Meta-analysis
}

\author{
$\mathrm{Nan} \mathrm{Hu}$ \\ Huazhong University of Science and Technology \\ $\mathrm{KeXu}$ \\ Huazhong University of Science and Technology \\ Chao Gong \\ Huazhong University of Science and Technology \\ Xizhen Xu ( $\nabla$ xzxu@tjh.tjmu.edu.cn) \\ Huazhong University of Science and Technology
}

\section{Research article}

Keywords: tooth loss, hypertension, meta-analysis

Posted Date: June 30th, 2020

DOl: https://doi.org/10.21203/rs.3.rs-38054/v1

License: (c) (i) This work is licensed under a Creative Commons Attribution 4.0 International License. Read Full License 


\section{Abstract}

Background: To investigate the bidirectional association between tooth loss and hypertension

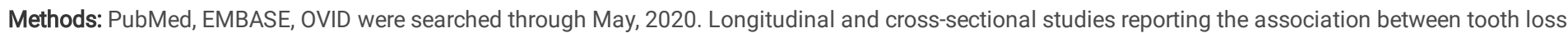

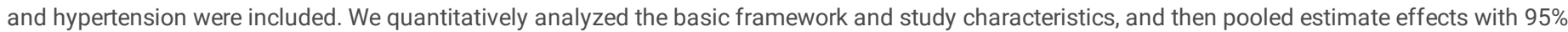
confidence intervals (Cls) of outcomes of each included studies using random-effects meta-analysis.

Results: This systematic review included sixteen studies involving about 188,000 participants. Quantitatively summarized results suggested, compared to individuals who have lost fewer than ten teeth, there was no significantly difference in the incidence of hypertension among participants who lost more than ten teeth (OR: $1.09,95 \% \mathrm{Cl}: 0.93,1.28)$. Besides, there is no significant difference of incident hypertension between individuals who ever lost teeth and never lost teeth (OR:1.03, 95\% Cl: 0.85,1.25). There was a significant association between hypertension and incidence of tooth loss (OR: 1.33, 95\% $\mathrm{Cl}$ : 1.04,1.70). Subgroup analysis by study design, age, gender ratio and religion showed statistically significant association between hypertension and incidence of tooth loss in specific subgroups.

Conclusions: This meta-analysis identified hypertension as a significantly risk factor of tooth loss while tooth loss was not an efficient predictor for incident hypertension. Considering the limited number of available researches and drawback of cross-sectional studies, more high-quality prospective studies of large sample sizes are needed to understand details of this bidirectional association. Since both tooth loss and hypertension are worldwide problems, our study provides new and comprehensive evidence for the prevention in oral complication of hypertensive patients.

\section{Background}

Hypertension, a chronic and persistent state of elevated blood pressure, has been reported to affect millions of people both in developed and developing countries and has been a growing public health problem worldwide ${ }^{[1]}$. A national report predicted that the worldwide prevalence of hypertension would reach $29.2 \%$ by $2025^{[2]}$. Besides, a large number of studies suggested that hypertension had close association with other systemic diseases including coronary heart disease, diabetes and chronic kidney disease, which might increase the risk of or promote the development of these diseases ${ }^{[3,4]}$. Despite the high prevalence and social burden, only a small part of hypertensive patients could control the blood pressure in an appropriate range ${ }^{[5]}$. Therefore, it's vital to find effective predictors for the early prevention and intervention for hypertension.

Tooth loss, an important index of oral health ${ }^{[6]}$, has been reported to be a possible complication of hypertension. Tooth loss reflects the end stage and irreversible condition of oral diseases including periodontitis ${ }^{[7]}$ while periodontitis might share the similar pathologic mechanisms with hypertension including chronic inflammatory state ${ }^{[8]}$. However, the results varied with studies and there was still not a comprehensive conclusion. Besides, several studies reported that tooth loss was positively associated with blood pressure levels and incidence of hypertension ${ }^{[9,10]}$. Tooth loss might be a potential predictor of hypertension.

Therefore, the aim of this systematic review and meta-analysis is to clarify the possibly bidirectional association between tooth loss and hypertension. Details about age, gender, region's interaction with tooth loss and hypertension would also be discussed in this study. A better understanding of the bidirectional association might offer effective indicators for the prevention of hypertension and tooth loss.

\section{Methods}

This study was performed according to the MOOSE (Meta-analysis Of Observational Studies in Epidemiology) guidelines ${ }^{[11] .}$

\section{Literature Search}

We identified relevant studies published from 1969 to May 2020 by searching on PubMed, EMBASE and OVID. Included studies were restricted to human species. We used the keywords "Tooth loss" or "Edentulous" in combination with "Hypertension". The full electronic search strategy for PubMed is ("tooth loss" [MeSH Terms] OR ("tooth"[All Fields] AND "loss"[All Fields]) OR "tooth loss"[All Fields]) OR (("mouth, edentulous"[MeSH Terms] OR ("mouth"[All Fields] AND "edentulous"[All Fields]) OR "edentulous mouth"[All Fields] OR "edentulous"[All Fields]) AND ("hypertension"[MeSH Terms] OR "hypertension"[All Fields])).

No restriction for study designs was applied. Relevant studies were also identified during the screen of literature reviews and reference lists of the search results. Titles and abstracts were screened during the initial selection after the exclusion of duplications. Further review was based on full texts. Nan Hu and Ke Xu screened all the articles independently. Their final results reached consensus. A senior reviewer (Xizhen Xu) would review the full text and make the decisions when there was disagreement. (Figure 1)

\section{Inclusion and Exclusion Criterion}

Studies were finally included if they satisfied the criteria: 1. Longitudinal studies or cross-sectional studies. 2.Studies explored the relationship between tooth loss and hypertension. 3. Comparators defined as participants without hypertension or diabetes and prediabetes patients without tooth loss, edentulism or who lost less than a certain number of tooth. 4. Studies that provide clear odds ratio (OR) or hazard ratio (HR) with $95 \%$ confidence interval (Cl) or original data which were necessary for calculating OR with $95 \% \mathrm{Cl}$. Studies would be excluded if they were: 1 . Duplications or same studies with similar study dates, unless they had different designs. 2. Studies that restricted the participants to specific population, such as patients with diabetes or other cardiovascular diseases in the baseline. 


\section{Data Extraction}

Data extraction was conducted independently by two reviewers (Nan Hu and Ke Xu). We collected authors, geographical region, publication year, sample size, mean age, gender ratio (female/male), the definition of exposure and comparator, study period, study design, endpoints, $\mathrm{HRs}$ or ORs with $95 \% \mathrm{Cl}$ from each eligible study. We extracted the HR or OR fully adjusted for covariates while there were results of different calculation models. If necessary, we would try to contact the corresponding author of relevant articles for further information.

\section{Quality assessment}

We used Newcastle-Ottawa Quality Assessment Scale (NOS) (http://www.ohri.ca/ programs/clinical-epidemiology/oxford.asp) to assess the quality of included longitudinal studies. Agency for Healthcare Research and Quality (AHRQ) Quality Indicators (https://www.ncbi.nlm.nih.gov/books/NBK35156/) were used to assess the quality of included cross-sectional studies. The assessment was performed by two reviewers (Nan Hu and Ke Xu) separately and one senior reviewer (Xizhen Xu) dealed with disagreement. (Table 1 and Supplementary File Tables)

\section{Definition}

Studies that hypertension fit the criterion of ICD (International Classification of Diseases)-10 were included, that is, a chronic condition of elevated blood pressure that systolic blood pressure reach or exceed $140 \mathrm{mmHg}$ or diastolic blood pressure reach or exceed $90 \mathrm{mmHg}$.

Tooth loss was defined as loss of the natural teeth except accidental one tooth loss or tooth loss caused by trauma, among which edentulism was defined as those who have lost more than 28 natural teeth.

\section{Statistical analysis}

Random-effects model to calculate the pooled HR/OR and $95 \% \mathrm{Cl}$. Heterogeneity was tested with the $\mathrm{I}^{2}$ statistic. We used Funnel plot asymmetry to detect publication bias, and defined significant publication bias as a p value $<0.1$. Sensitivity analysis was used to examine the stability of the pooled results, whereby each study was omitted at a time and recalculated the pooled HR of the rest studies. Subgroup analysis was conducted by study design, age, gender and region. Meta-analysis was performed with Stata software (version 16.0; College station, TX, USA). All p values were two-side with a significant level at 0.05 .

\section{Results}

\section{Literature selection}

In our study, a total of 294 studies were considered for further review, including the results of key words search ( $\mathrm{n}=290)$ and additional records identified from relevant reviews and reference lists of other studies $(n=4)$. Through the careful reading of full texts, seven cohort studies ${ }^{[12-18]}$ and nine cross-sectional studies $^{[19-27]}$ were thought eligible for meta-analysis (Figure 1). Six included studies ${ }^{[12-16,19]}$ reported the association between tooth loss and incident hypertension, among which one study ${ }^{[15]}$ reported incidence of diabetes among participants with edentulism. The other nine studies reported the association between hypertension and incidence of tooth loss, among which four studies ${ }^{[24-27]}$ were concerned on the incidence of edentulism. The main information of eligible studies was given in Table 1. Funnel plot suggested that there was no significant evidence for publication bias (Supplementary File Figure 1). The assessment of the quality of included longitudinal studies by NOS showed their scores were no less than 6 points therefore they were both considered moderate or high quality (total score=9 points) (Table 1 and Supplementary File Table 1 and Table 2).

\section{Risk of bias assessment for included studies}

\section{Bias from character of population}

The diversity of included population suggested potential different professions, socioeconomic status, income level and health level, which might partly contribute to the bias of synthesized results.

\section{Bias from covariates adjustment}

Included studies provided different information of covariates adjustment. Six included studies ${ }^{[12,13,16,21,24,26]}$ adjusted the results for age, four ${ }^{[12,13,24,26]}$ adjusted for gender and three ${ }^{[12,13,15]}$ adjusted for BMI, among which one study ${ }^{[12]}$ further adjusted for current smokers, glycaemia, cholesterol, and deprivation score; one study ${ }^{[16]}$ further adjusted for comprehensive smoking index, family history of hypertension, race, dental profession, diabetes diagnosis, alcohol consumption, body mass index, physical activity, fruit and vegetable intake, vitamin E, vitamin D, and calcium intake, and multivitamin supplement use; one ${ }^{[21]}$ further adjusted for annual family income, working hours, shift work, duration of employment, and night shift; one ${ }^{[13]}$ further adjusted for diabetes, dyslipidemia, estimated glomerular filtration rate, smoking status, daily alcohol intake, daily fruit intake, daily sugar-sweetened soft drink intake, physical

activity, and nocturnal sleep duration; one ${ }^{[15]}$ further adjusted for education, and pack-years smoking and another one ${ }^{[26]}$ further adjusted for residential area. Eight included studies ${ }^{[14,17-20,22,23,25,27]}$ didn't provide information of covariates adjustment.

\section{Bias from study design}

There were seven cohort studies and eight cross-sectional studies included in our analysis. There difference between study design and the restrictions of cross-sectional studies might contribute the bias of our results. 
Our result suggested that compared to individuals who have lost fewer than ten teeth, there was no significantly change in the incidence of hypertension among participants who lost more than ten teeth (OR: $1.09,95 \% \mathrm{Cl}: 0.93,1.28)$. Besides, there is no significant difference of incident hypertension between individuals who ever lost teeth and never lost teeth (OR:1.03,95\% Cl: $0.85,1.25)$. We noticed that the heterogeneity was considerable for this part $\left(\mathrm{I}^{2}=89.8 \%\right.$, $p=0.000$ ). Considering the limited number of the included studies, we failed to decrease the heterogeneity by excluding any studies. Difference both in study design and covariates adjustment might contribute to the high heterogeneity. Another included study ${ }^{[19]}$ showed that compared to participants who lost no more than three teeth, people who lost more than four natural teeth have a higher risk of incident hypertension (OR: 1.48, 95\%Cl: 1.30,1.69). (Figure 2$)$

\section{Incidence of tooth loss among individuals with hypertension}

There was a significant association between hypertension and incidence of tooth loss (OR: 1.33, 95\% Cl: 1.04,1.70). Separately, there was significant association between hypertension and incidence of tooth loss but not edentulism (OR: $1.53,95 \% \mathrm{Cl}: 1.15,2.03)$ while the similar result was not reported for edentulous patient (OR: $0.97,95 \% \mathrm{Cl}: 0.79,1.20)$. The heterogeneity was significant $\left(I^{2}=72.9 \%, p=0.000\right)$ and sensitivity analysis didn't show the main source of heterogeneity. We failed to reduce the heterogeneity by excluding the studies one by one. After reviewing the whole articles, we noticed that one study limited the participant to professional drivers and white-collar workers while other included studies didn't set a restriction for participants. Besides, different study design and covariates adjustment might contribute to the high heterogeneity. (Figure 3 and Supplementary File Figure 2)

\section{Subgroup analysis}

Subgroup by study design suggested that there was a significant relationship between tooth loss and incident hypertension in cross-sectional studies (OR:1.35, 95\% Cl:1.01,1.82) while for longitudinal study, the result was not significant (OR:1.30, 95\% Cl:0.93,1.82). (Table 2)

The age-specific subgroup analysis showed that for individuals less than 65 years old, hypertension was significantly associated with incidence of tooth loss (>45: OR:2.35, 95\% Cl:1.22,4.51; [45-65]: OR: 1.33, 95\% Cl:1.04,1.69). However, there was no significant association between hypertension and incident tooth loss among participants over 65 years old (OR: $0.97,95 \% \mathrm{Cl}: 0.79,1.18)$. Subgroup by gender ratio suggested that for population with gender ratio (female/male) $\geq 1$, hypertension was significantly associated with incident tooth loss (OR: $1.39,95 \%$ Cl: $1.05,1.86)$ while there was no significant association between hypertension and incidence of tooth loss for population with gender ratio (female/male) <1 (OR:1.13, 95\% Cl:0.75, 1.70). Subgroup by region showed that hypertension was significantly associated with tooth loss in Middle Asia (OR:1.73, 95\% Cl: 1.41,2.13) but not in East Asia (OR:1.10, 95\% Cl:0.93,1.31) and North America (OR:1.84, 95\% Cl:0.82,4.12). (Table 2)

The heterogeneity was considerate between studies among participants under the age of 45 years old $\left(I^{2}=86.8 \%, p=0.006\right)$, with gender ratio (female/male) $\geq 1\left(\mathrm{I}^{2}=79.7 \%, \mathrm{p}=0.000\right)$ and in North America $\left(\mathrm{I}^{2}=.84 .1 \%, \mathrm{p}=0.002\right)$. After reviewing the articles, we noticed different source of participants, health status in the baseline, covariates adjustment and other associated factors might contribute to the significant heterogeneity. (Table 2)

\section{Discussion}

This meta-analysis has quantitatively examined the bidirectional relationship between tooth loss and hypertension. A total of 16 studies were included. There were about 177,000 participants in the pooled analysis of the incident hypertension among individuals with tooth loss and 7,600 participants in the pooled analysis of the incident tooth loss among individuals with hypertension.

\section{The effectiveness of tooth loss as a predicator of incident hypertension}

In general, there was no significant association between tooth loss and incidence of hypertension, no matter the number of tooth loss. As the included studies were all longitudinal, we confirmed that the result was credible. However, one study ${ }^{[19]}$ showed that individuals who lost more than three natural teeth were more likely to develop hypertension compared to individuals lost less than three teeth. Firstly, the study was a cross-sectional study which couldn't reveal the substantial sequence of tooth loss and hypertension. Secondly, the definition of exposure and comparator was different from other included studies which might result in the different result. Besides, we noticed that the result in the study varied with the number of lost teeth and stage of hypertension. Compared with individuals lost no more than three teeth, participants lost more than 15 teeth showed no significant difference in incidence of hypertension, which was partly consistent with our pooled analysis. Therefore, though several studies showed that tooth loss might act as a predictor for diabetes ${ }^{\text {[28, } 29]}$ and metabolic syndrome ${ }^{[30]}$, there is still no comprehensive evidence for the effectiveness of tooth loss as a predicator of incident hypertension. However, our result didn't repudiate the possibility that after the number of tooth loss exceed a certain number, the incidence of hypertension might increase. It was reported that tooth loss was associated with increased blood pressure (not fit the criterion of hypertension) in adults ${ }^{[31]}$. More high-quality prospective cohort studies remained to be done to reveal the curve between the number of tooth loss and incident hypertension.

\section{The risk of tooth loss among individuals with hypertension}

Our result suggested that hypertension was significantly associated with incidence of tooth loss. Consistent with our study, a recent review showed that hypertension could predict tooth loss among patients with periodontitis ${ }^{[32]}$. Therefore, individuals with hypertension should pay more attention to the oral health. It was reported that long-term periodontal maintenance might improve the oral health and decrease the incidence of tooth loss ${ }^{\text {[3] }}$, which might also apply to patients with hypertension. We noticed that there was no significant association between hypertension and incident edentulism, which was reported for the first time. Since the risk of tooth loss (except edentulism) increased among patients with hypertension, the risk of edentulism should increase, too. After discussion, we concluded that the diagnostic criterion of edentulism was much harder to be fit than other types of tooth loss which resulted in the relatively 
low incidence of being edentulous compared to tooth loss and might further contribute to the unexpected result. Besides, subgroup by study design showed that there was no significant association between hypertension and incident tooth loss according to longitudinal studies while among cross-sectional studies, the relationship was significant. Considering the drawback of cross-sectional study, we should be cautious about the result. More high-quality prospective studies remain to be done to reveal the substantial relationship between hypertension and tooth loss.

To obtain more clinically specific results, we conducted subgroup analysis by age, gender ratio and religion. According to our results, the OR between hypertension and incident tooth loss declined with age, and the significant association only existed among individuals no more than 65 years old. Epidemiology research showed that the prevalence of severe tooth loss increased gradually with age and reached a peak at about 65 years old ${ }^{[34]}$. We guess that older people might pay more attention to their oral health and care of teeth which might partly counteract the effect of hypertension on tooth loss. Besides, the incidence of other risk factors of tooth loss including diabetes ${ }^{[35]}$ and metabolic syndrome ${ }^{[36]}$ showed an increase with age which might reduce the correlation between hypertension and tooth loss. There was still no satisfied explanation for this problem and more work remained to be conducted.

Subgroup by gender ratio (female/male) suggested that hypertension was significantly associated with tooth loss in population of which female made up the majority. The similar result didn't apply to population with gender ratio (female/male) $<1$. It was the first time to be reported. Previous studies have suggested that smoking, diabetes and their combination with hypertension was associated with high risk of periodontitis ${ }^{[37,38]}$, which might further result in tooth loss

${ }^{[39]}$. To the best of our knowledge, males are more likely than females to smoke cigarette and develop diabetes ${ }^{[40,41]}$. Therefore, the correlation between hypertension and incidence and tooth loss should be higher in male than female. We noticed that the heterogeneity was considerable in population with gender ratio (female/male) $\geq 1$ which decrease the credibility of the result. Besides, the included studies with gender ratio (female/male) were all conducted in Japan which might cause the bias of the result.

Region-specific analysis showed different results in different regions. Hypertension was significantly associated with tooth loss only in Middle Asia but not in East Asia and North America. Both race and income level were reported to be associated with tooth loss ${ }^{[42,43]}$. People with high income level tend to care more about their oral health which might reduce the incidence of tooth loss. Besides, the dietary patterns, smoking and alcohol consumption were all related to the oral health ${ }^{[44,45]}$. All of these might contribute to the different results of the association between hypertension and incidence of tooth loss.

In conclusion, our result suggested that individuals with hypertension should pay more attention to their oral health to prevent excessive tooth loss, especially for people no more than 65 years old and Middle Asia.

\subsection{Biological mechanisms}

Increasing studies has been done to explore the potential mechanisms of tooth loss and hypertension. Basically, we concluded the following three aspects of common mechanisms for tooth loss and hypertension. Firstly, hypertension was reported to be associated with chronic inflammation. It has been demonstrated in numerous clinical trials that hypertensive patients commonly have increased plasma CRP levels ${ }^{[46-48]}$. Besides, studies have showed higher plasma IL-6, IL-1 $\beta$, and TNF- $a$ levels in hypertensive patients compared to normotensive patients ${ }^{[49]}$. All the inflammatory factors might promote the occurrence of periodontitis, and cause tooth loss. Secondly, hypertension was associated with vascular dysfunction and might result in arteriosclerosis and microcirculation disorders ${ }^{[50,51]}$, which might influence the blood supply of root of tooth, promote oral infection and result in tooth extraction. Lastly, patients with hypertension show a high risk of developing other chronic diseases, including diabetes, metabolic syndrome and coronary heart disease, all of which was reported to be associated with tooth loss ${ }^{[32,52,53]}$. Combined with these chronic diseases, hypertensive patients might experience an earlier and severer tooth loss.

\section{Strengths and limitations}

The strengths of our study are as follows. Firstly, the study was the first systematic analysis and meta-analysis focused on the bidirectional relationship between hypertension and tooth loss in the recent twenty years and we further discussed the effects of age, gender and religion on the association. Secondly, the quality of included longitudinal studies were moderate or high, which contributed to the high reliability. Thirdly, we systematically analyzed the bidirectional association between tooth loss and hypertension, which provided the new and comprehensive evidence for reducing the heavy burden of tooth loss.

There were limitations of our study in the following aspects. Firstly, considering the limited number of longitudinal studies, cross-sectional studies were included in meta-analysis which might reduce the credibility of results and cause the defect of proving causality relationship. Secondly, the number of included studies is not enough, especially for subgroup-analysis. Thirdly, several pooled results showed a high heterogeneity while we failed to reduce it by extracting several studies. Fourthly, part of our included studies didn't provide the OR with $95 \% \mathrm{Cl}$ that we needed for analysis so we calculate them by ourselves which might cause bias of the results. Besides, we failed to obtain the comprehensive curves of the number of lost teeth and the incidence of hypertension due to the lack of data. Lastly, diabetes, BMI, smoking status and other factors might also have an interaction with tooth loss and hypertension, which was not discussed in the study.

\section{Recommendations for future research}

\section{Study design}

We suggest high-quality prospective cohort studies with detailed baseline information and regular health examination as ideal study method. Population with different features including a specific job or different age groups and gender composition should be recorded and synthesized by stratified analysis. Smoking 
status, alcohol consumption, mental health, geographical region and other potential factors should be taken into consideration for the improvement of the representativeness.

\section{The number of lost tooth}

Future studies should record the number of teeth that participants lost and divide them into different groups. The association between tooth loss and hypertension need more quantification.

Adjustment by covariates

We found various covariates which may exert unstable impact on the summary during the review of eligible studies. We recommend standardized covariates should include at least age, gender, race, BMI, alcohol consumption, smoking status, health level in the baseline, socioeconomic status at an individual level. This work requires detailed and elaborate baseline information.

\section{Conclusions}

This study identified hypertension as a risk factor of tooth loss while tooth loss was not an efficient predictor for incidence of hypertension. Considering the limited number of included researches, more high-quality and prospective cohort studies with large sample sizes are needed to understand details of the bidirectional association. As both tooth loss and hypertension are worldwide problems, our study provides new and comprehensive evidence for the prevention of oral complication of hypertension.

\section{Declarations}

\section{Ethical approval and consent to participate}

Ethical approval and consent to participate were not necessary for this systematic review.

\section{Consent for publication}

Not applicable

\section{Availability of data and materials}

All data analyzed during this study are included in published articles

\section{Authors' contributions}

Nan Hu: design of the work and writing of the main manuscript; Ke Xu: design of the work and the analysis of the data; Chao Gong: data extraction; Xizhen Xu: design of the work and revision of the main manuscript. All authors have read and approved the manuscript.

\section{Acknowledgments}

Authors would like to thank all the authors of the original articles.

\section{Funding}

Not applicable

\section{Competing interests}

None declared

\section{References}

1. Cheng, F., et al., Tooth loss and risk of cardiovascular disease and stroke: A dose-response meta analysis of prospective cohort studies. 2018. 13(3): $\mathrm{p}$. e0194563.

2. Kearney, P.M., et al., Global burden of hypertension: analysis of worldwide data. Lancet, 2005. 365(9455): p. 217-23.

3. Kalaitzidis, R.G. and M.S. Elisaf, Treatment of Hypertension in Chronic Kidney Disease. Curr Hypertens Rep, 2018. 20 (8): p. 64.

4. Escobar, E., Hypertension and coronary heart disease. J Hum Hypertens, 2002. 16 Suppl 1: p. S61-3.

5. Elliott, W.J., Systemic hypertension. Curr Probl Cardiol, 2007. 32(4): p. 201-59.

6. Mojon, P., J.M. Thomason, and A.W. Walls, The impact of falling rates of edentulism. Int J Prosthodont, 2004. 17(4): p. 434-40.

7. Nazir, M.A., et al., The burden of Diabetes, Its Oral Complications and Their Prevention and Management. Open Access Maced J Med Sci, 2018. 6(8): p. 1545-1553.

8. Taguchi, A., et al., Tooth loss is associated with an increased risk of hypertension in postmenopausal women. Hypertension, 2004. 43(6): p. 1297-300. 
9. Holmlund, A., G. Holm, and L. Lind, Severity of periodontal disease and number of remaining teeth are related to the prevalence of myocardial infarction and hypertension in a study based on 4,254 subjects. J Periodontol, 2006. 77(7): p. 1173-8.

10. Rivas-Tumanyan, S., et al., Periodontal disease, hypertension, and blood pressure among older adults in Puerto Rico. J Periodontol, 2013. 84(2): p. 203-11.

11. Stroup, D.F., et al., Meta-analysis of observational studies in epidemiology: a proposal for reporting. Meta-analysis Of Observational Studies in Epidemiology (MOOSE) group. Jama, 2000. 283(15): p. 2008-12.

12. Darnaud, C., et al., Oral Health and Blood Pressure: The IPC Cohort. Am J Hypertens, 2015. 28(10): p. 1257-61.

13. Iwashima, Y., et al., Additive interaction of oral health disorders on risk of hypertension in a Japanese urban population: the Suita Study. Am J Hypertens, 2014. 27(5): p. 710-9.

14. Dar-Odeh, N., et al., Association of Dental Caries, Retained Roots, and Missing Teeth with Physical Status, Diabetes Mellitus and Hypertension in Women of the Reproductive Age. Int J Environ Res Public Health, 2019. 16(14).

15. Gordon, J.H., et al., Association of Periodontal Disease and Edentulism With Hypertension Risk in Postmenopausal Women. Am J Hypertens, 2019. 32(2): p. 193-201.

16. Rivas-Tumanyan, S., et al., Periodontal disease and incidence of hypertension in the health professionals follow-up study. Am J Hypertens, 2012. 25(7): $\mathrm{p}$. 770-6.

17. Mihara, Y., et al., Occlusal support predicts tooth loss in older Japanese people. Community Dent Oral Epidemiol, 2020. 48(2): p. 163-170.

18. Yoshino, K., et al., Tooth Loss in Problem-oriented, Irregular, and Regular Attenders at Dental Offices. Bull Tokyo Dent Coll, 2016. 57(1): p. 11-9.

19. Da, D., et al., Association between tooth loss and hypertension among older Chinese adults: a community-based study. BMC Oral Health, 2019. 19(1): $\mathrm{p}$. 277.

20. Delgado-Perez, V.J., et al., Diabetes or hypertension as risk indicators for missing teeth experience: An exploratory study in a sample of Mexican adults. Niger J Clin Pract, 2017. 20(10): p. 1335-1341.

21. Suzuki, S., et al., Comparison of risk factors for tooth loss between professional drivers and white-collar workers: an internet survey. Ind Health, 2016. 54(3): p. 246-53.

22. Northridge, M.E., et al., A community-based oral public health approach to promote health equity. Am J Public Health, 2015.105 Suppl 3: p. S459-65.

23. Al-Shammari, K.F., et al., Risk indicators for tooth loss due to periodontal disease. J Periodontol, 2005. 76(11): p. $1910-8$.

24. Xie, Q. and A. Ainamo, Association of edentulousness with systemic factors in elderly people living at home. Community Dent Oral Epidemiol, 1999. 27(3): p. 202-9.

25. Islas-Granillo, H., et al., Edentulism risk indicators among Mexican elders 60-year-old and older. Arch Gerontol Geriatr, 2011. 53(3): p. 258-62.

26. Jung, S.H., J.I. Ryu, and D.B. Jung, Association of total tooth loss with socio-behavioural health indicators in Korean elderly. J Oral Rehabil, 2011. 38(7): p. 517-24.

27. Nakahori, N., et al., Socioeconomic status and remaining teeth in Japan: results from the Toyama dementia survey. BMC Public Health, 2019. 19(1): $\mathrm{p}$. 691.

28. Liljestrand, J.M., et al., Missing Teeth Predict Incident Cardiovascular Events, Diabetes, and Death. J Dent Res, 2015. 94(8): p. 1055-62.

29. Chang, Y., et al., Improved oral hygiene is associated with decreased risk of new-onset diabetes: a nationwide population-based cohort study. Diabetologia, 2020. 63(5): p. 924-933.

30. Souza, M.L., et al., Association between metabolic syndrome and tooth loss: A systematic review and meta-analysis. J Am Dent Assoc, 2019. 150(12): p. 1027-1039.e7.

31. Peres, M.A., et al., Tooth loss is associated with increased blood pressure in adults-a multidisciplinary population-based study. J Clin Periodontol, 2012. 39(9): p. 824-33.

32. Helal, O., et al., Predictors for tooth loss in periodontitis patients: Systematic review and meta-analysis. J Clin Periodontol, 2019.46 (7): p. 699-712.

33. Fardal, O., P. Fardal, and G.R. Persson, Periodontal and general health in long-term periodontal maintenance patients treated in a Norwegian private practice: a descriptive report from a compliant and partially compliant survivor population. J Periodontol, 2013. 84(10): p. $1374-81$.

34. Kassebaum, N.J., et al., Global Burden of Severe Tooth Loss: A Systematic Review and Meta-analysis. J Dent Res, 2014. 93(7 Suppl): p. 20s-28s.

35. Balakumar, P., U.K. Maung, and G. Jagadeesh, Prevalence and prevention of cardiovascular disease and diabetes mellitus. Pharmacol Res, 2016. 113(Pt A): p. 600-609.

36. Saklayen, M.G., The Global Epidemic of the Metabolic Syndrome. Curr Hypertens Rep, 2018. 20(2): p. 12.

37. Segura-Egea, J.J., et al., Relationship between smoking and endodontic variables in hypertensive patients. J Endod, 2011. 37(6): p. 764-7.

38. Offenbacher, S., et al., Impact of tooth loss on oral and systemic health. Gen Dent, 2012. 60(6): p. 494-500; quiz p. 501-2.

39. Ramseier, C.A., et al., Natural history of periodontitis: Disease progression and tooth loss over 40 years. J Clin Periodontol, 2017. 44(12): p. 1182-1191.

40. Kékes, E., et al., [The prevalence of smoking and gender differences according to the data of the national health screening program in 2010-2018]. Orv Hetil, 2019. 160(52): p. 2047-2053.

41. Wild, S., et al., Global prevalence of diabetes: estimates for the year 2000 and projections for 2030. Diabetes Care, 2004. 27(5): p. 1047-53.

42. Dye, B., et al., Dental caries and tooth loss in adults in the United States, 2011-2012. NCHS Data Brief, 2015(197): p. 197.

43. Seerig, L.M., et al., Tooth loss in adults and income: Systematic review and meta-analysis. J Dent, 2015. 43(9): p. $1051-1059$.

44. Zhu, Y. and J.H. Hollis, Tooth loss and its association with dietary intake and diet quality in American adults. J Dent, 2014. 42(11): p. 1428-35.

Page $7 / 11$ 
45. Hach, M., et al., Social inequality in tooth loss, the mediating role of smoking and alcohol consumption. Community Dent Oral Epidemiol, 2019. 47(5): $\mathrm{p}$. 416-423.

46. Xiao, Q., et al., Changes of Plasma Tumor Necrosis Factor a and C-Reactive Protein Levels in Patients with Hypertension Accompanied by Impaired Glucose Tolerance and their Clinical Significance. Asian Pac J Cancer Prev, 2015. 16(8): p. 3389-93.

47. Rashmi, N., et al., Assessment of C-reactive Proteins, Cytokines, and Plasma Protein Levels in Hypertensive Patients with Apical Periodontitis. J Contemp Dent Pract, 2017. 18(6): p. 516-521.

48. Guven, A., et al., Increased platelet activation and inflammatory response in patients with masked hypertension. Blood Coagul Fibrinolysis, 2013. 24(2): p. 170-4.

49. Dinh, Q.N., et al., Roles of inflammation, oxidative stress, and vascular dysfunction in hypertension. Biomed Res Int, 2014. 2014: p. 406960.

50. Pessina, A.C., et al., [Hypertension and arteriosclerosis]. Ann Ital Med Int, 1992. 7(3 Suppl): p. 112s-118s.

51. Strain, W.D. and P.M. Paldánius, Diabetes, cardiovascular disease and the microcirculation. Cardiovasc Diabetol, $2018.17(1):$ p. 57.

52. Souza, M.L., et al., Association between metabolic syndrome and tooth loss: A systematic review and meta-analysis. J Am Dent Assoc, 2019. 150(12): p. 1027-1039.e7.

53. Cheng, F., et al., Tooth loss and risk of cardiovascular disease and stroke: A dose-response meta analysis of prospective cohort studies. PLoS One, 2018. 13(3): p. e0194563.

\section{Tables}

Table 1 Characteristics of the included studies

\begin{tabular}{|c|c|c|c|c|c|c|c|c|c|c|}
\hline Part & Study & Area & $\begin{array}{l}\text { Study } \\
\text { Period }\end{array}$ & $\begin{array}{l}\text { Total } \\
\text { Sample }\end{array}$ & $\begin{array}{l}\text { Mean } \\
\text { Age(Years) }\end{array}$ & Gender(female/male) & Exposure & Comparator & Endpoints & Study Des \\
\hline \multirow[t]{6}{*}{ I } & $\begin{array}{l}\text { Dar-Odeh, N. } \\
\text { et al (2019) }\end{array}$ & $\begin{array}{l}\text { Saudi } \\
\text { Arabia }\end{array}$ & $\begin{array}{l}2018- \\
2019\end{array}$ & 1768 & 31.2 & All women & tooth loss & $\begin{array}{l}\text { No tooth } \\
\text { loss }\end{array}$ & Hypertension & $\begin{array}{l}\text { Retrospec } \\
\text { study }\end{array}$ \\
\hline & $\begin{array}{l}\text { Gordon, J.H. } \\
\text { et al (2019) }\end{array}$ & USA & $\begin{array}{l}1998- \\
2015\end{array}$ & 36692 & $67.0-69.7$ & All women & Edentulism & $\begin{array}{l}\text { No tooth } \\
\text { loss }\end{array}$ & Hypertension & Prospectiv \\
\hline & $\begin{array}{l}\text { Da, D. et al } \\
(2019)\end{array}$ & China & $\begin{array}{l}2010- \\
2012\end{array}$ & 3677 & 70.2 & $2033 / 1644$ & $\begin{array}{l}\text { Tooth } \\
\text { loss }>=4\end{array}$ & $\begin{array}{l}\text { Tooth } \\
\text { loss }<=3\end{array}$ & Hypertension & $\begin{array}{l}\text { Cross-sect } \\
\text { study }\end{array}$ \\
\hline & $\begin{array}{l}\text { Darnaud .C } \\
\text { et al (2015) }\end{array}$ & USA & $\begin{array}{l}2002- \\
2011\end{array}$ & 102330 & 43.5 & $37.2 / 62.3$ & $\begin{array}{l}\text { Tooth loss } \\
>10\end{array}$ & $\begin{array}{l}\text { Tooth loss } \\
\leq 10\end{array}$ & Hypertension & Prospectiv \\
\hline & $\begin{array}{l}\text { Iwashima, Y } \\
\text { et al .(2014) }\end{array}$ & Japan & $\begin{array}{l}2008- \\
2012\end{array}$ & 1643 & 56.6 & $56.6 / 43.4$ & $\begin{array}{l}\text { Tooth loss } \\
>10\end{array}$ & $\begin{array}{l}\text { Tooth loss } \\
\leq 10\end{array}$ & Hypertension & Prospectiv \\
\hline & $\begin{array}{l}\text { Rivas- } \\
\text { Tumanyan,S. } \\
\text { et al (2012) }\end{array}$ & USA & $\begin{array}{l}1986- \\
2006\end{array}$ & 31543 & $71-82$ & All men & Tooth loss & $\begin{array}{l}\text { No tooth } \\
\text { loss }\end{array}$ & Hypertension & Prospectiv \\
\hline \multirow[t]{10}{*}{ II } & $\begin{array}{l}\text { Mihara, Y. et } \\
\text { al (2020) }\end{array}$ & Japan & $\begin{array}{l}2010- \\
2017\end{array}$ & 528 & $>70$ & $245 / 283$ & Hypertension & $\begin{array}{l}\text { Not } \\
\text { hypertension }\end{array}$ & Tooth loss & Prospectiv \\
\hline & $\begin{array}{l}\text { Nakahori et } \\
\text { al (2019) }\end{array}$ & Japan & 2014 & $275 / 898$ & $>65$ & $1840 / 1666$ & Hypertension & $\begin{array}{l}\text { Not } \\
\text { hypertension }\end{array}$ & Edentulous & $\begin{array}{l}\text { Cross-sect } \\
\text { study }\end{array}$ \\
\hline & $\begin{array}{l}\text { Delgado- } \\
\text { Perez, V. J. et } \\
\text { al (2017) }\end{array}$ & USA & 2012 & 60 & 50.7 & $30 / 30$ & Hypertension & $\begin{array}{l}\text { Not } \\
\text { hypertension }\end{array}$ & Tooth loss & $\begin{array}{l}\text { Cross-sect } \\
\text { study }\end{array}$ \\
\hline & $\begin{array}{l}\text { Yoshino, K. } \\
\text { et al (2016) }\end{array}$ & Japan & $\begin{array}{l}2000- \\
2014\end{array}$ & 1400 & 61.7 & $714 / 686$ & Hypertension & $\begin{array}{l}\text { Not } \\
\text { hypertension }\end{array}$ & Tooth loss & $\begin{array}{l}\text { Retrospec } \\
\text { study }\end{array}$ \\
\hline & $\begin{array}{l}\text { Suzuki, S. et } \\
\text { al (2016) }\end{array}$ & Japan & 2015 & 920 & 49.3 & All men & Hypertension & $\begin{array}{l}\text { Not } \\
\text { hypertension }\end{array}$ & Tooth loss & $\begin{array}{l}\text { Cross-sect } \\
\text { study }\end{array}$ \\
\hline & $\begin{array}{l}\text { Northridge, } \\
\text { M. E. et al } \\
\text { (2015) }\end{array}$ & USA & $\begin{array}{l}2010- \\
2012\end{array}$ & 556 & $>50$ & $409 / 137$ & Hypertension & $\begin{array}{l}\text { Not } \\
\text { hypertension }\end{array}$ & Tooth loss & $\begin{array}{l}\text { Cross-sect } \\
\text { study }\end{array}$ \\
\hline & $\begin{array}{l}\text { Islas- } \\
\text { Granillo, H.et } \\
\text { al (2011) }\end{array}$ & Mexico & 2000 & 139 & 79 & $96 / 43$ & Hypertension & $\begin{array}{l}\text { Not } \\
\text { hypertension }\end{array}$ & Edentulous & $\begin{array}{l}\text { Cross-sect } \\
\text { study }\end{array}$ \\
\hline & $\begin{array}{l}\text { Jung, S. H. et } \\
\text { al (2011) }\end{array}$ & Korea & 2005 & 828 & $>65$ & $30 / 20$ & Hypertension & $\begin{array}{l}\text { Not } \\
\text { hypertension }\end{array}$ & Edentulous & $\begin{array}{l}\text { Cross-sect } \\
\text { study }\end{array}$ \\
\hline & $\begin{array}{l}\text { Al- } \\
\text { Shammari, } \\
\text { K. F. et al } \\
(2005)\end{array}$ & Kuwait & 2004 & 1775 & 39.8 & $984 / 701$ & Hypertension & $\begin{array}{l}\text { Not } \\
\text { hypertension }\end{array}$ & Tooth loss & $\begin{array}{l}\text { Cross-sect } \\
\text { study }\end{array}$ \\
\hline & $\begin{array}{l}\text { Xie, Q et al } \\
(1999)\end{array}$ & China & $\begin{array}{l}1990- \\
1991\end{array}$ & 293 & $>76$ & $208 / 85$ & Hypertension & $\begin{array}{l}\text { Not } \\
\text { hypertension }\end{array}$ & Edentulous & $\begin{array}{l}\text { Cross-sect } \\
\text { study }\end{array}$ \\
\hline
\end{tabular}


Note: Part I Tooth loss and incident hypertension; Part II Hypertension and incident tooth loss

Abbreviation: USA the United States

Table 2 Subgroup-analysis of hypertension and incident tooth loss

\begin{tabular}{|c|c|c|c|c|c|}
\hline \multirow[t]{2}{*}{ Subgroup } & \multirow[t]{2}{*}{ Stratum } & \multirow[t]{2}{*}{ Number of studies } & \multirow[t]{2}{*}{ Pooled OR $(95 \% \mathrm{Cl})$} & \multicolumn{2}{|c|}{ Text of heterogeneity } \\
\hline & & & & $R(\%)$ & $P$ value \\
\hline \multirow[t]{3}{*}{ Age } & $<45$ years old & 2 & $2.35(1.22,4.51)$ & 86.8 & 0.006 \\
\hline & 45-65 years old & 3 & $1.33(1.04,1.69)$ & 0.0 & 0.738 \\
\hline & $>65$ years old & 5 & $0.97(0.79,1.18)$ & 0.0 & 0.703 \\
\hline \multirow[t]{2}{*}{ Gender ratio(female/male) } & $<1$ & 3 & $1.13(0.75,1.70)$ & 79.7 & 0.000 \\
\hline & $\geq 1$ & 8 & $1.39(1.05,1.86)$ & 0.0 & 0.616 \\
\hline \multirow[t]{2}{*}{ Study design } & Longitudinal & 2 & $1.30(0.93,1.82)$ & 6.8 & 0.300 \\
\hline & Cross-sectional & 9 & $1.35(1.01,1.82)$ & 77.3 & 0.000 \\
\hline \multirow[t]{3}{*}{ Region } & Middle Asia & 1 & $1.73(1.41,2.13)$ & & \\
\hline & East Asia & 7 & $1.10(0.93,1.31)$ & 10.3 & 0.350 \\
\hline & North America & 3 & $1.84(0.82,4.12)$ & 84.1 & 0.002 \\
\hline
\end{tabular}

Abbreviations: OR, Odds ratio. $\mathrm{Cl}$, Confidence interval.

$P$ is the value of total variation clarified by heterogeneity.

\section{Figures}

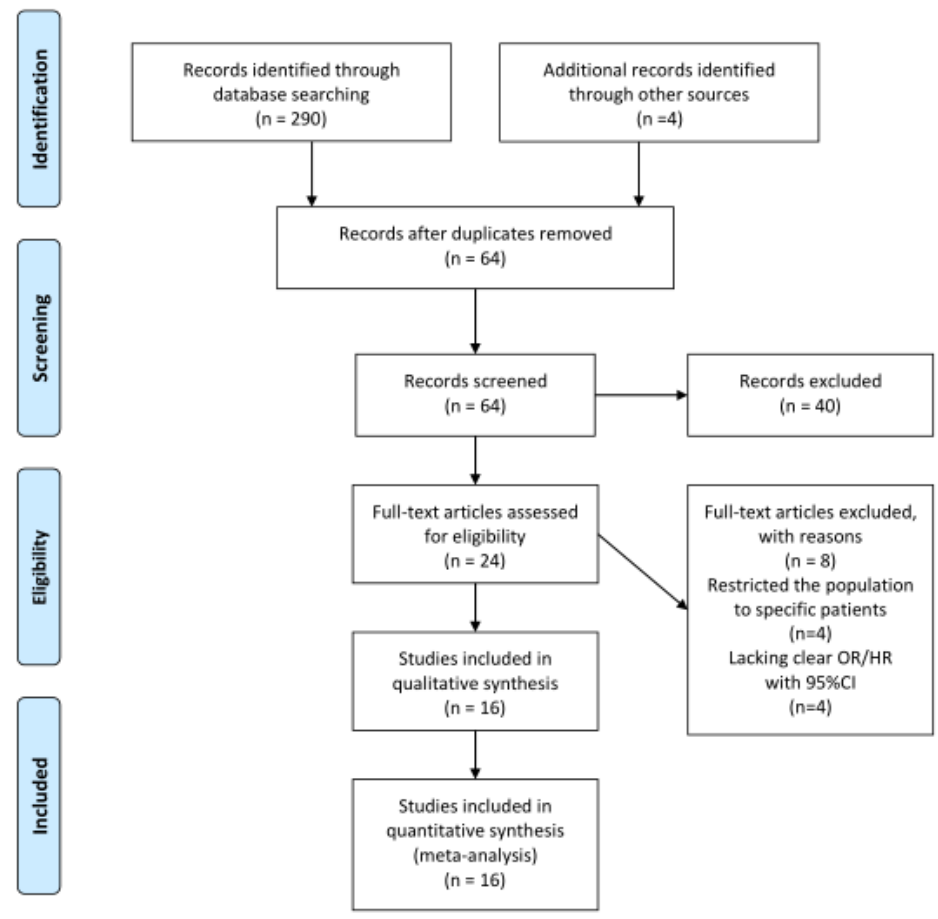

Figure 1. Results of systematic literature search

Figure 1

Results of systematic literature search 


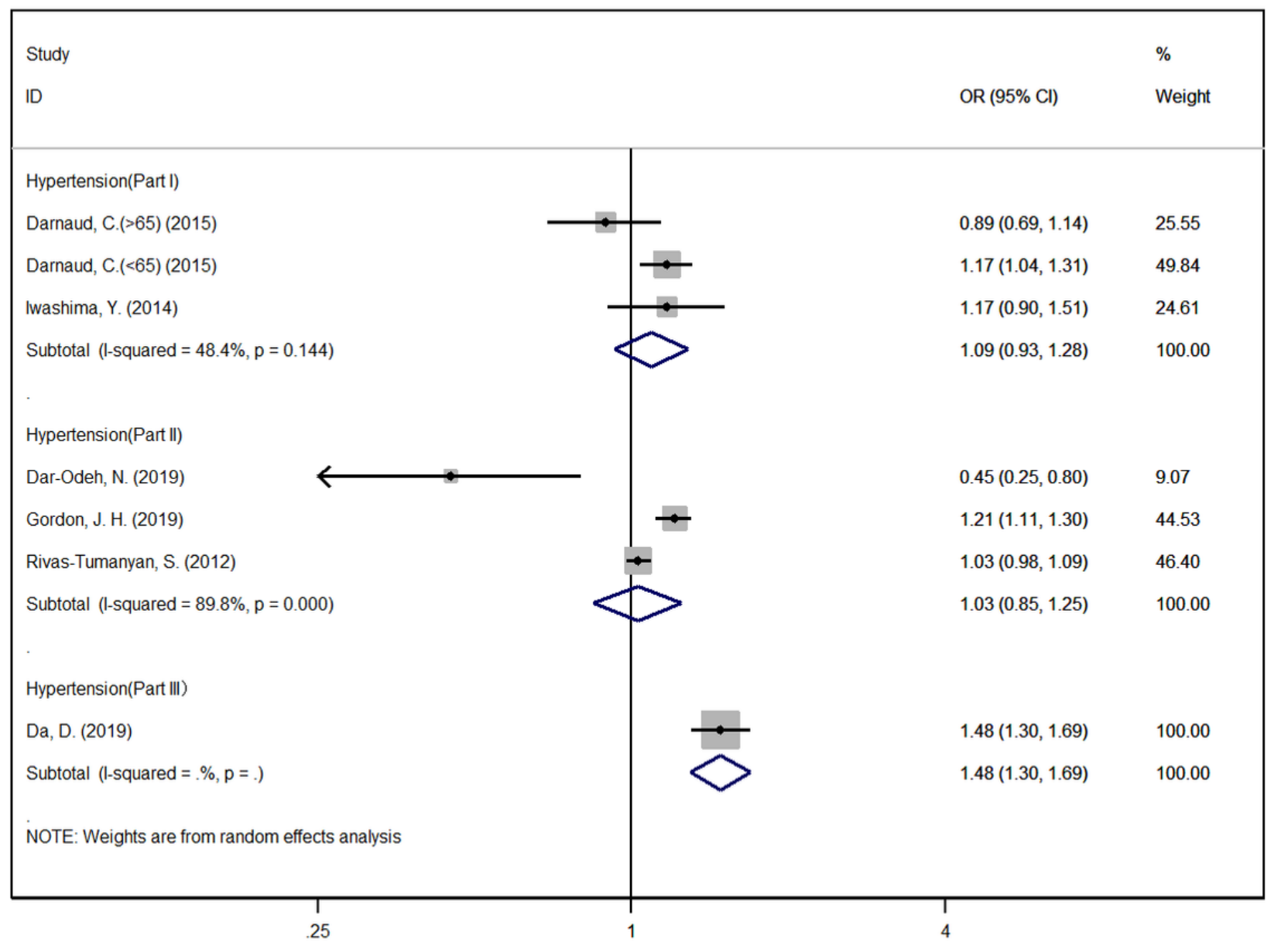

\section{Figure 2}

Tooth loss and incident hypertension Note: Part I the comparison between individuals lost more than ten teeth and no more than ten teeth; Part II the comparison between individuals ever lost tooth and never lost teeth; Part III the comparison between individuals lost more than three teeth and no more than three teeth 


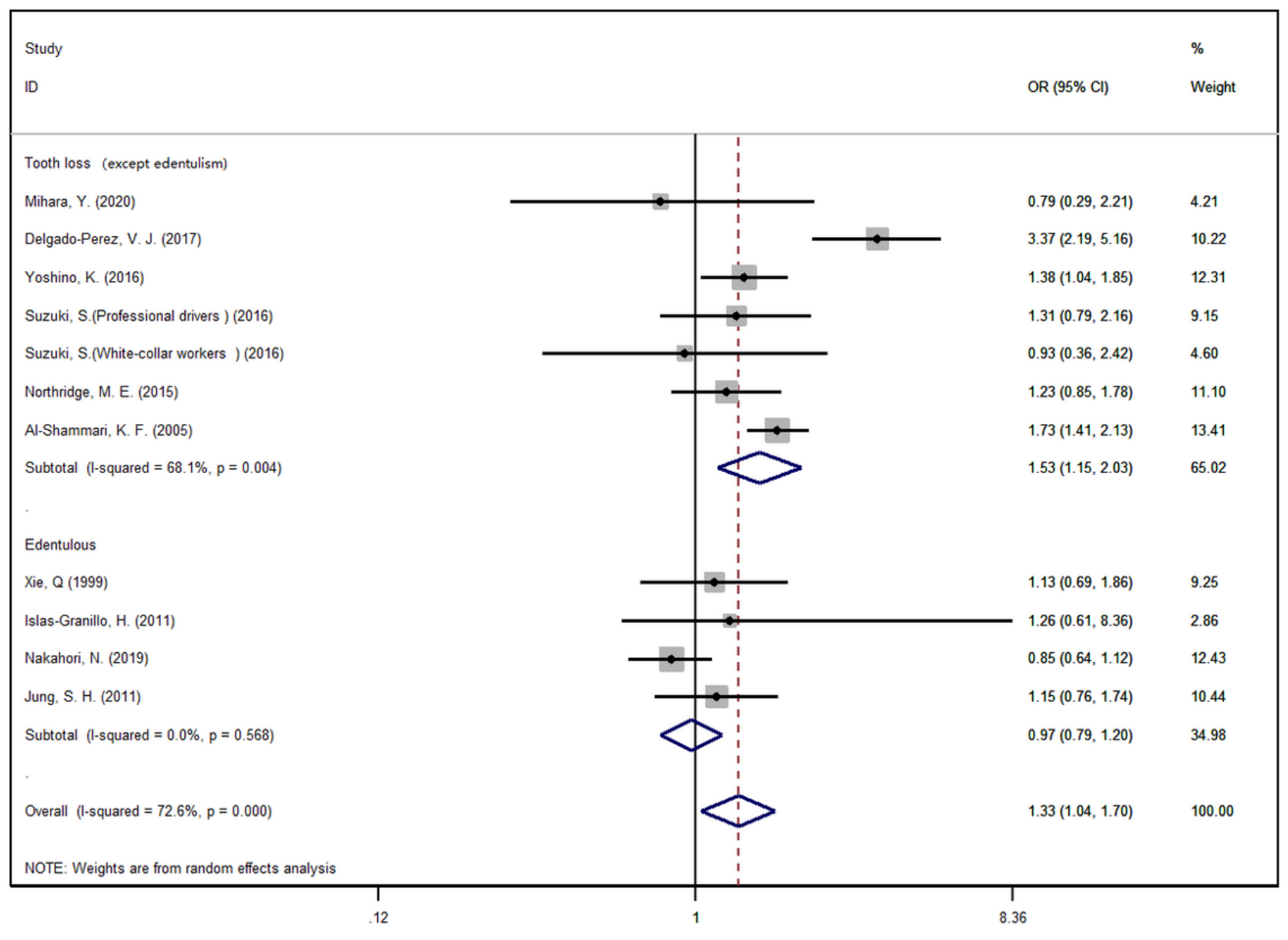

\section{Figure 3}

Hypertension and incident tooth loss

\section{Supplementary Files}

This is a list of supplementary files associated with this preprint. Click to download.

- SupplementaryFilesFigure1.jpg

- SupplementaryFilesFigure2.jpg

- SupplementaryFliesTable.docx 